\title{
CROP SPECIES RECOGNITION AND DISCRIMINATION PADDY-RICE-GROWING- FIELDS FROM REAPED-FIELDS BY THE RADAR VEGETATION INDEX (RVI) OF ALOS-2/PALSAR2
}

\author{
Y. Yamada ${ }^{\text {a }}$

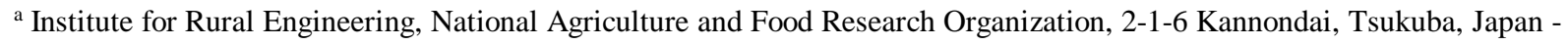 \\ yamaday@affrc.go.jp
}

Commission VIII, WG VIII/8

KEY WORDS: radar vegetation index, RVI, ALOS-2, PALSAR2, crop, biomass, rice, paddy fields

\begin{abstract}
:
The Japanese ALOS-2 satellite was launched on May 24 ${ }^{\text {th }}$, 2014. It has the L-band SAR, PALSAR-2. Kim,Y. and van Zyl, J.J. proposed a kind of Radar Vegetation Index (RVI) as RVI $=8 * \sigma{ }^{0} \mathrm{hv} /\left(\sigma{ }^{0} \mathrm{hh}+\sigma^{0}{ }_{\mathrm{vv}}+2 * \sigma{ }^{0} \mathrm{hv}\right)$ by L-band full-polarimetric radar data. Kim, Y. and Jackson,T.J., et al. applied the equation into rice and soybean by multi-frequency polarimetric scatterometer above 4.16 meters from the ground. Their report showed the L-band was the most promising wave length for estimating LAI and NDVI from RVI. The author tried to apply the analysis to the actual paddy field areas, both Inashiki region and Miyagi region in the eastern main island, ñHonshuò, areas of Japan by ALOS-2/PALSAR-2 full-polarimetry data in the summer season, the main crop growing time, of 2015. Judging from conventional methods, it will be possible to discriminate paddy rice growing fields from reaped fields or the other crops growing fields by the PALSAR-2 data. But the RVI value is vaguely related to such land use or biomass at the present preliminary experiment. The continuous research by the additional PALSAR-2 full-polarimetry data should be desired.
\end{abstract}

\section{INTRODUCTION}

Most of the earth-observation-satellite in operating now, are the satellite equipped with SAR sensors. Japanese SAR satellites are the L-band SAR. But as its polarization is only $\mathrm{HH}$ polarization and its wave length is rather long, the estimation of paddy-rice-planting-area is only for practical use.

As SAR data of earth surface can be obtained in case of cloudy weather, this is an advantage of agricultural applications, such as crop species recognition or estimation of crop biomass. All-weather data collection characteristic using the L-band SAR is important for agricultural applications.

\section{RADAR VEGETARTION INDEX (RVI)}

\subsection{History of RVI}

Kim and van Zyl (2001) proposed a kind of radar vegetation index (RVI). RVI $=4 * \min (\lambda 1, \lambda 2, \lambda 3) /(\lambda 1+\lambda 2+\lambda 3)$ They modified the equation as follows. (2009)

$\mathrm{RVI}=8 * \sigma^{0} \mathrm{hv} /\left(\sigma^{0} \mathrm{hh}+\sigma^{0} \mathrm{vv}+\sigma^{0} \mathrm{hv}\right)$

by L-band full-polarimetric SAR data. They applied it into rice crop and soybean. (Kim, Jackson et al., 2012) Their experiment was performed by the L-band full polarization sensor above the field collecting data every 10 minutes during the crop grown season. They compared RVI for L-, C- and Xbands to crop growth data, LAI and NDVI. They found L-band RVI was well correlated with Vegetation Water Content, LAI and NDVI. But the field data were collected by the multifrequency polarimetric scatterometer. The platform height was 4.16 meters from the ground. And they reported that the RVI is effective to estimate VWC, vegetation water content. Their VWC is useful for the estimation of soil moisture or drought, according to Kim and Jackson, et al.

\subsection{Method of RVI caliculation}

The ALOS-2/PALSAR-2 JAXA processing level 1.1 data and level1.5 are converted from the DN (digital number) into backscattering values by the following equation.

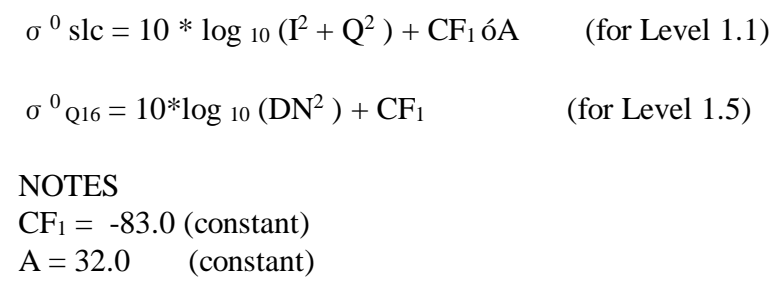

Every digital number for $\mathrm{HH}, \mathrm{HV}, \mathrm{VV}$, which mean the polarization, were converted into NRCS number. And RVI, radar vegetation index, was calculated by the following equation.

$\mathrm{RVI}=\left(8 * \stackrel{\mathrm{U}}{0}_{\mathrm{HV}}\right) /\left(\stackrel{\mathrm{U}}{0}_{\mathrm{HH}}+\stackrel{\mathrm{U}}{0}^{0} \mathrm{vV}+2 * \stackrel{\mathrm{u}}{0}_{\mathrm{HV}}\right)$

(RVI: radar vegetation index)

\section{STUDY AREA}

The field survey area was both sides along the lower course of 
stream of theò Toneò river in the Kanto plain of Central part of Japan. There are upland wheat fields or lotus paddy fields scattered among paddy rice fields in this area. Lotus roots are a kind of foodstuff of Japanese dishes. Geographical features are flat and somewhere its drain is bad. Therefore there are some drainage pump stations in this area. And field data were collected on August $17^{\text {th }}$ and $24^{\text {th }}, 2015$. Its items were whether the paddy rice was still growing or already reaped, what kind of crop was, such as paddy rice, barley, wheat, lotus roots. Paddy rice is including cereals, forage-grain-rice, whole-cropsilage rice plant.(Figure 2., Figure 3.) Lotus root is a kind of ingredients for Japanese cuisine.

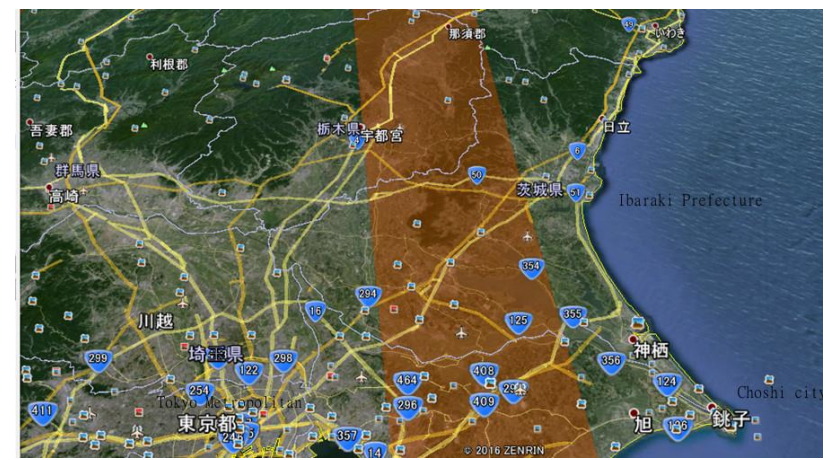

Figure1. Study area near Tokyo and ALOS-2 observation strip of land (red- coloured-band-image, on the Google earth)
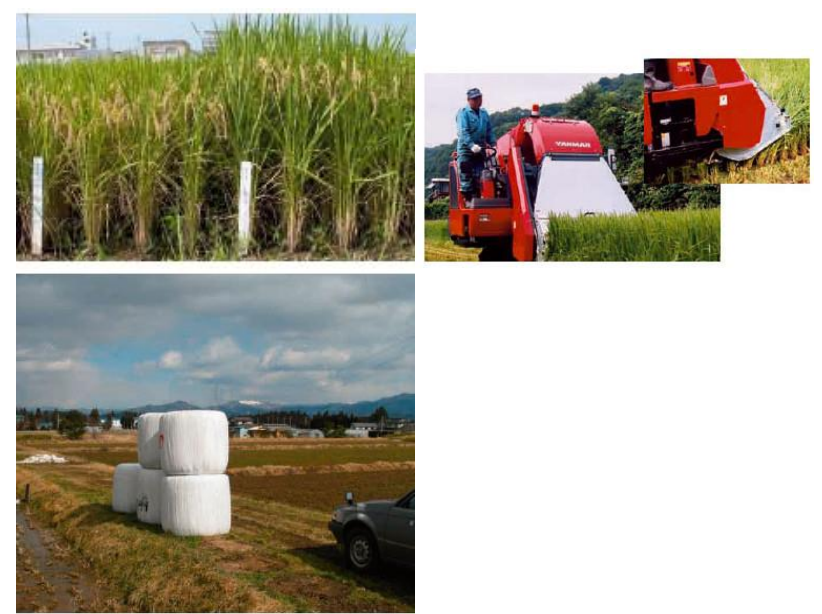

Figure 2. Whole-crop-silage-paddy rice, its harvest and its rollbale-silage (Ministry of Agriculture, Forestry and Fisheries, 2016a)

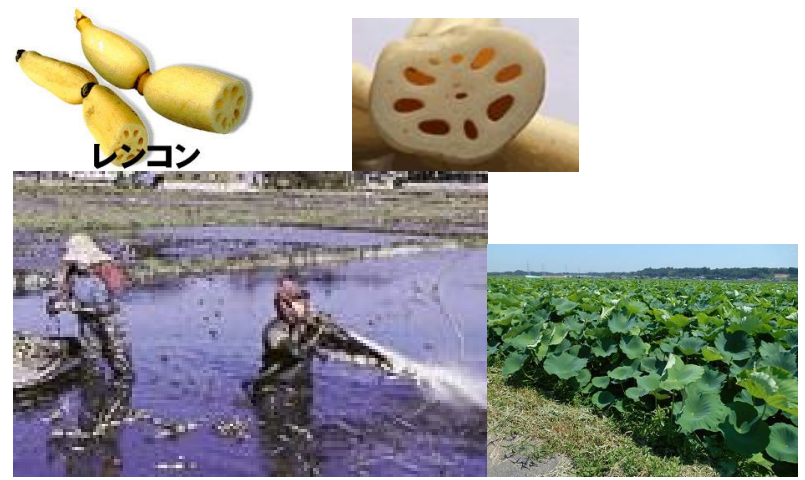

Figure 3. Lotus roots and its harvest in a lotus pond (Ministry of Agriculture, Forestry and Fisheries, 2016b)

\section{SATELLITE DATA}

The ALOS-2/PALSAR2 satellite was launched on May $24^{\text {th }}$, 2014 and its data distribution to the public was started on Nov. $25^{\text {th }}, 2014$. The opportunity of full-polarimetry data acquisition around Japan is limited as the following table at the first observation year.

\begin{tabular}{|c|c|c|c|}
\hline Cycle & Start date & Descending & Ascending \\
\hline 28 & 03-Aug-15 & Any mode & $\mathrm{FP}(3) \mathrm{R} 25^{\circ}$ \\
\hline 29 & 17-Aug-15 & $\begin{array}{l}\mathrm{W} 2(2) \mathrm{R} \\
26.2^{\circ}-41.8^{\circ}\end{array}$ & $\mathrm{FP}(4) \mathrm{R} 28^{\circ}$ \\
\hline 30 & 31-Aug-15 & $\begin{array}{l}\mathrm{U} 2(6) \mathrm{R} \\
29.1^{\circ}\end{array}$ & $\mathrm{FP}(5) \mathrm{R} 30.4^{\circ}$ \\
\hline 31 & 14-Sep-15 & $\begin{array}{l}\mathrm{U} 2(7) \mathrm{R} \\
32.4^{\circ}\end{array}$ & $\mathrm{FP}(6) \mathrm{R} 32.7^{\circ}$ \\
\hline 32 & 28-Sep-15 & $\begin{array}{l}\mathrm{U} 2(8) \mathrm{R} \\
35.4^{\circ}\end{array}$ & $\mathrm{FP}(7) \mathrm{R} 34.9^{\circ}$ \\
\hline
\end{tabular}

Table 1. ALOS-2/PALSAR2 observation plan around Japan

The ALOS-2/PALSAR2 data on August $25^{\text {th }}, 2015$ were used in this study. The data processing levels were level 1.1 and level 1.5 by JAXA and RESTEC format (CEOS format).

\section{CONVENTIONAL METHOD}

The Entropy-Alpha(H-alpha) decomposition method is one of the conventional analytical method for in-coherent scattering. Its result both sides along the lower óToneô river course was shown in Figure 4. as follows. This calculation process was done by the polSARpro software, ver 5.04. The result image was rather rough, so its version might have some software bugs.

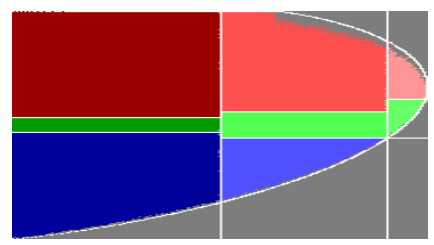

H-alpha classification plane

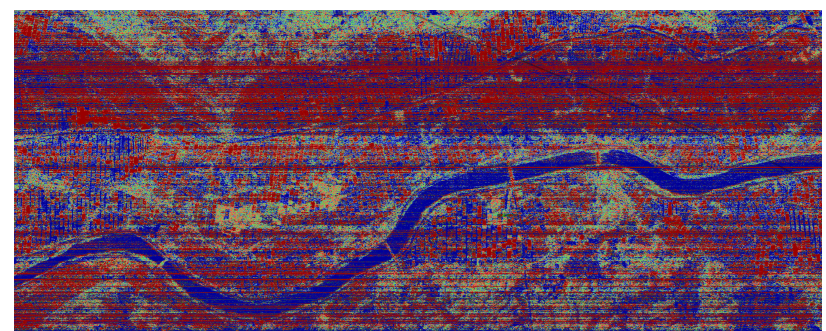

Figure 4. H-alpha decomposition

AS for another conventional method, there was the Yamaguchiôs 4 components decomposition method. The result was divided into 4 parts, odd, double, volume, helix scattering. (Figure 5.) It seems to represent the right condition of land use. 


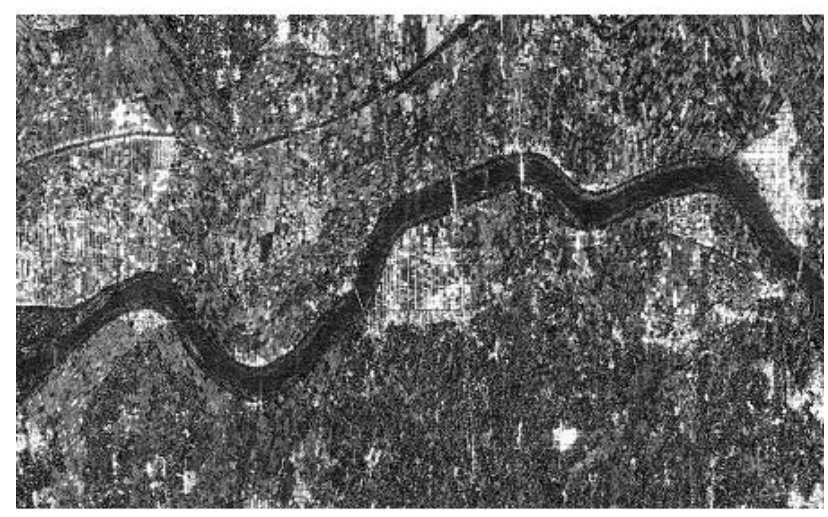

Odd

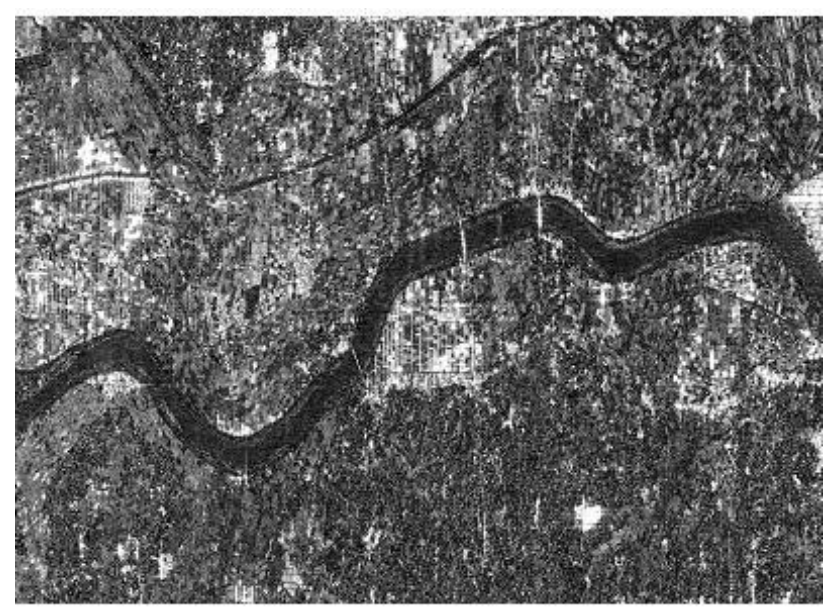

$\mathrm{Dbl}$

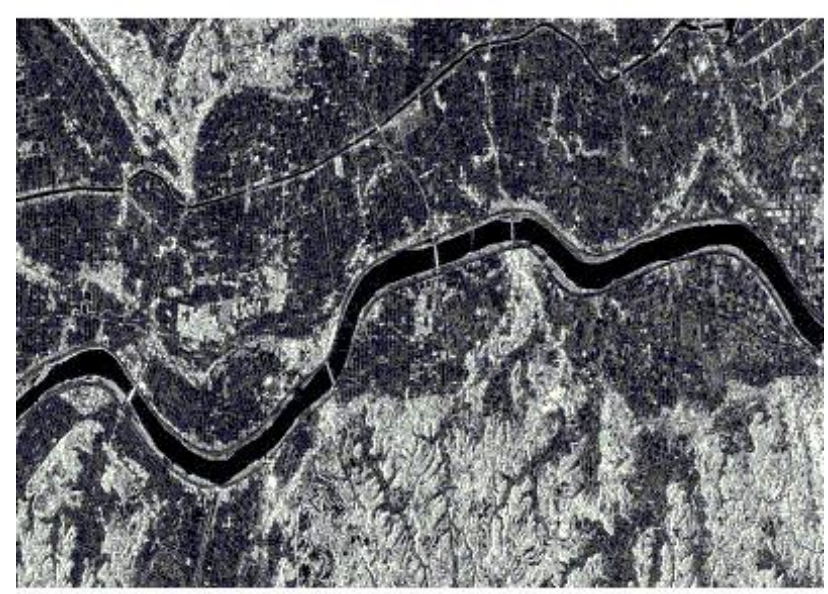

Vol

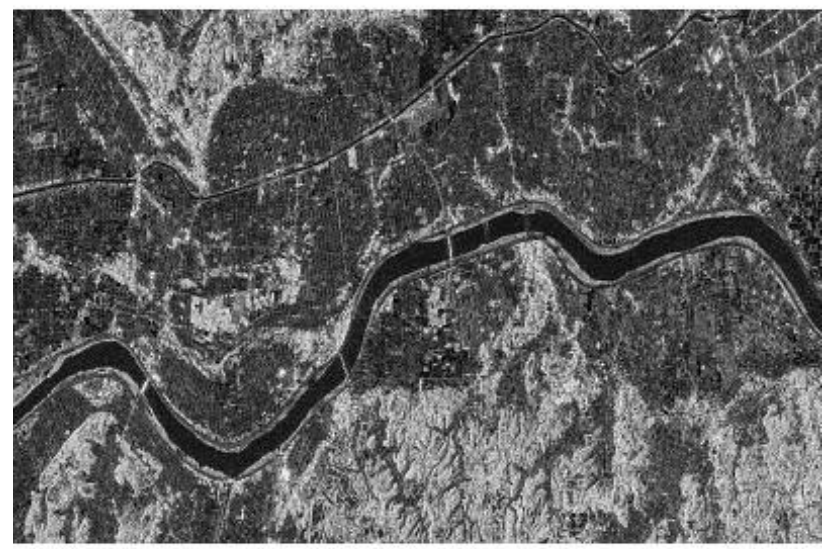

Hlx

Figure 5. Yamaguchiôs 4-Component Decomposition

The Wishhart H/A/Alpha classification method is a kind of unsupervised classification methods. (Figure 6.)

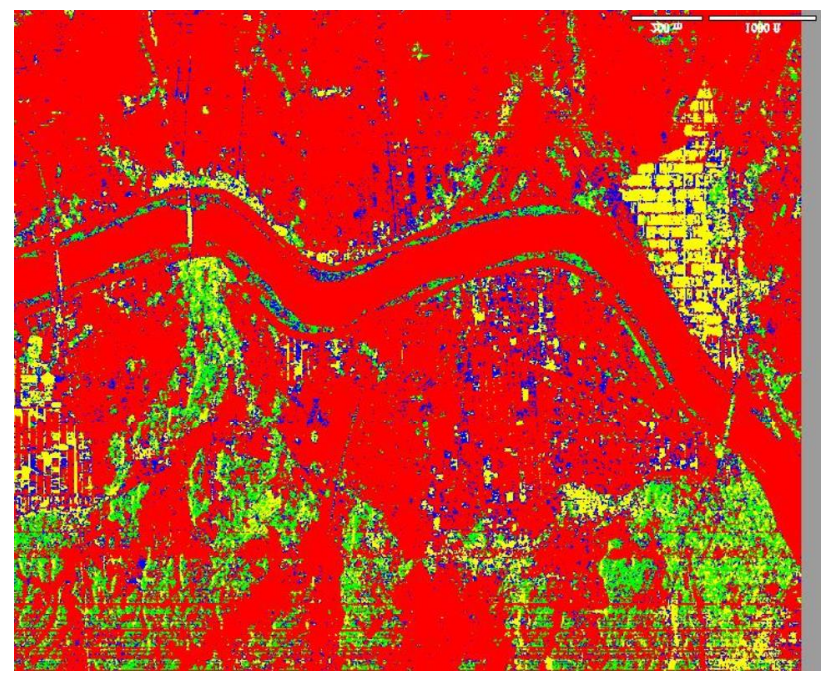

Figure 6. Wishart supervised classification

\section{RVI RESULT}

The Radar Vegetation Index (RVI) result and field survey data in this area was indicated in Fugure 7. The white coloured rectangles meant mainly the reaped paddy rice fields and lotus ponds or soy bean upland fields. The zoomed image were shown in Figure 8, 9, 10, 11. The higher RVI value showed in warm color, red, yellow in those figures. And the cold color meant lower RVI value. But the relation of RVI value to the biomass in their fields were vague, not clear. 


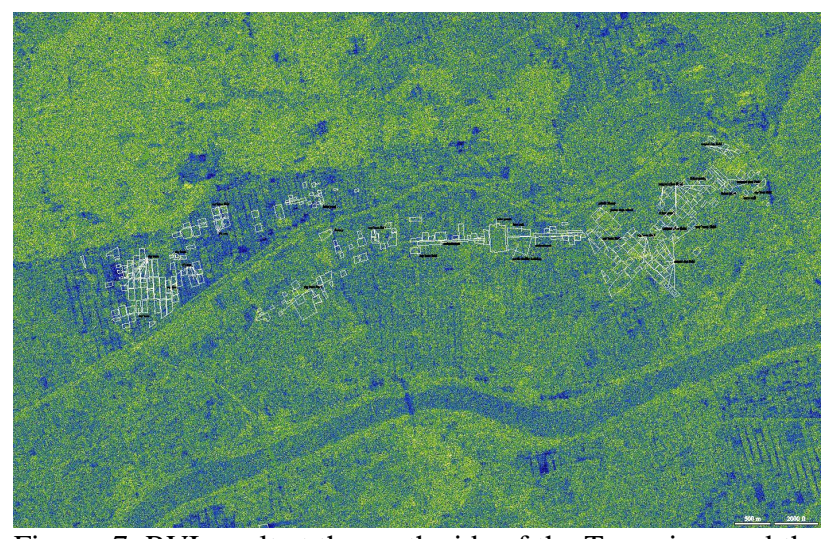

Figure 7. RVI result at the north side of the Tone river and the overlaid-gound-survey-map

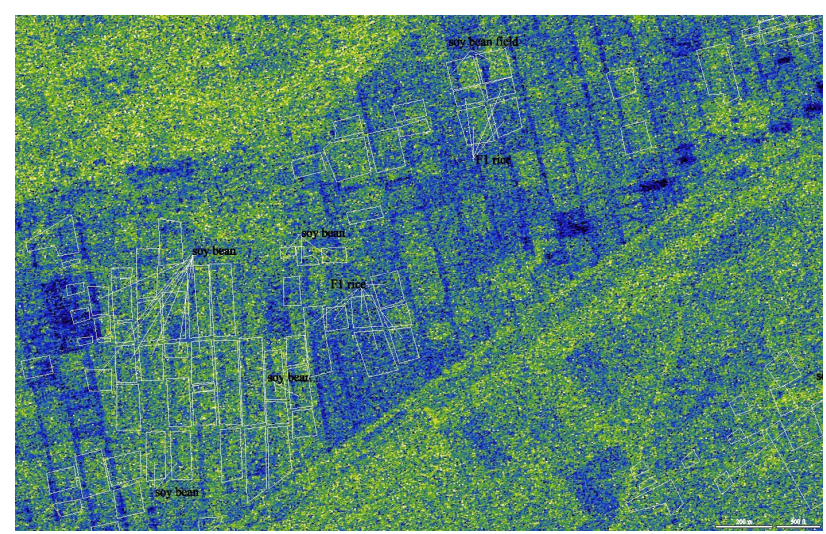

Figure 8. Zooming the RVI result of upper left part of Figure 7. image

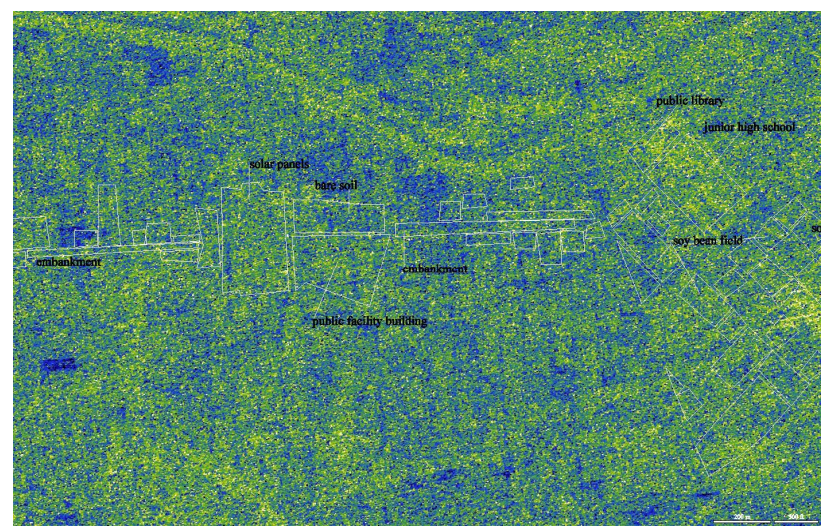

Figure 9. Zooming the RVI result of middle part of Figure 7. image

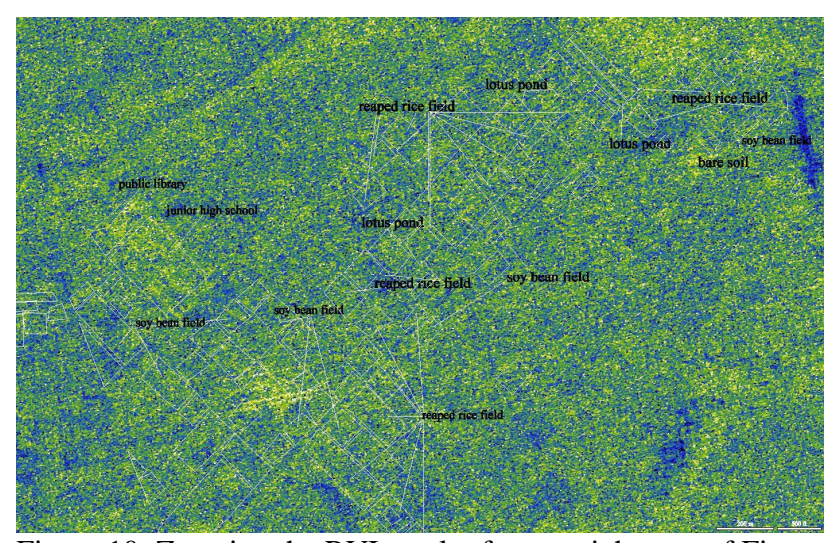

Figure 10. Zooming the RVI result of upper right part of Figure 7. image

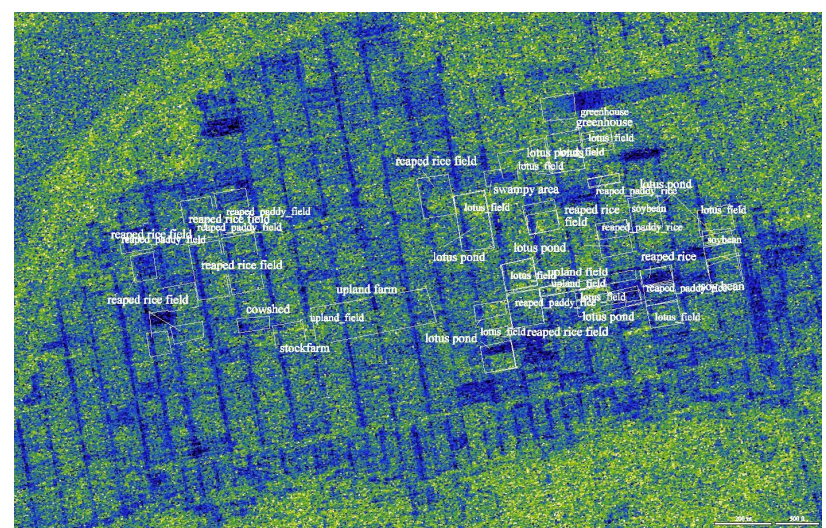

Figure 11. the RVI result of the south side of the Tone river

\section{FINDINGS AND DISCUSSION}

The Radar Vegetation Index (RVI) was promising and great expectative index for agriculture. Although the RVI result of scatter meter over the rice and soy beans in the near length were good agreement with plantôs biomass in the past research paper (Kim, Jackson, 2012), the RVI from ALOS-2/PALSAR2 satellite radar was not so good.

But this is only one-year and once result. Further research should be desired.

\section{REFERENCES}

Inoue, Y., Kurosu,T., et al., 2002, Season-long daily measurements of multifrequency $(\mathrm{Ka}, \mathrm{Ku}, \mathrm{X}, \mathrm{C}$, andL) and full-polarization backscatter signatures over paddy rice field and their relationship with biological variables, Remote Sens. of Environ., 81, 194-204

Kim,Y. and van Zyl, J.J., 2009, A Time-Series Approach to Estimate Soil Moisture Using Polarimetric Radar Data, IEEE Trans. on Geo. Remote Sens., Vol.47 No.8, 25192527 
Kim,Y., Jackson,T., et al., 2012,Radar Vegetation Index for Estimating the Vegetation Water Content of Rice and Soybean, IEEE Geo. Remote Sens. Letters, Vol.9, No.4, 564-568

Kim,Y., Jackson,T., et al., 2014, Retrieval of Wheat Growth Parameters With Radar Vegetation Indices, IEEE Geo. and Remote Sens. Letters, Vol.11, No.4, 808812

Ministry of Agriculture, Forestry and Fisheries of Japan a, https://www.s.affrc.go.jp/docs/report/report15/no15_p1.h tm (Viewing on April 11th, 2016, partially edited.)

Ministry of Agriculture, Forestry and Fisheries of Japan b, http://www.maff.go.jp/j/agri_school/a_menu/oseti/04.ht $\mathrm{ml}$ (Viewing on April 11th, 2016, partially edited.)

Yamada,Y., 2015,PRELIMINARY STUDY ON

THE RADAR VEGETATION INDEX (RVI) APPLICATION TO ACTUAL PADDY FIELDS BY ALOS/PALSAR FULL-POLARIMETRY SAR DATA, Proc. of 36 th ISRSE, 166-1, 166-3 